\title{
Análisis de los gustos recreativos en el Parque Ambiental Bicentenario de Metepec, Estado de México (México)
}

\section{Ramiro Flores-Xolocotzi}

Colegio de Tlaxcala (México)

\begin{abstract}
Resumen: Se realizó un estudio en el Parque Ambiental Bicentenario para identificar gustos/preferencias recreativas de los visitantes y determinar su relación con variables sociodemográficas. Además se identificaron problemas que afectan el servicio recreativo que presta el Parque. Los resultados obtenidos a través de correlación canónica no lineal y regresiones logísticas, indican que las actividades familiares y el deporte son actividades frecuentes/importantes, no así el servicio de educación ambiental dirigido particularmente a niños que no es citado como una actividad frecuente ni favorita. Además se observan conflictos entre usuarios del equipamiento recreativo. Consecuentemente, es necesario que se desarrollen programas recreativos dirigidos a todo tipo de usuarios; además de consensuar y fomentar el respeto a reglas de uso del equipamiento.
\end{abstract}

Palabras clave: Recreación; Espacios urbanos; Áreas verdes; Ciudades; Turismo regional.

Title: Analysis of recreational tastes Bicentennial Environmental Park Metepec, State of Mexico (Mexico)

Abstract: An investigation was conducted in Environmental Bicentennial Park to identify recreational uses of visitors and determine their relationship with sociodemographic variables. Furthermore identify problems that affect the recreational service provided by the Park. The results obtained through nonlinear canonical correlation and logistic regressions, indicate that family activities and sports are important activities, while that environmental education service aimed particularly at children who are not cited as a frequent or favorite activity. There are also conflicts between users of recreational equipment. Consequently, it is necessary to develop recreational programs aimed at all users, in addition to consensus and promote respect for rules of use of equipment.

Keywords: Recreation; Urban space; Green areas; Cities; Regional tourism.

i Colegio de Tlaxcala A.C. (México). Profesor-Investigador en el Colegio de Tlaxcala. E-mail: pinos42@hotmail.com 


\section{Introducción}

Los parques urbanos proporcionan diversos servicios: ambientales (provisión de oxígeno y captura de carbono) y sociales (recreación). El reconocimiento actual de los servicios que prestan los parques, ha llevado a su revalorización dentro de los programas de planificación urbana (Falcón, 2007). Consecuentemente, la demanda por espacios verdes que cubran las necesidades de sus visitantes, ha sensibilizado a los tomadores de decisiones y especialistas en la necesidad de conocer los gustos recreativos en parques y la percepción que los usuarios tienen de los espacios (Low et al., 2005). De este modo, la demanda de servicios recreativos en ciudades, es particularmente importante debido a su acceso gratuito, particularmente en personas que no tienen ingresos para acceder a servicios de tipo privado (Oguz, 2000). Hay que considerar también, que los parques urbanos son espacios abiertos con atractivos turísticos de interés derivados de los servicios que prestan (actividades deportivas, programas de educación ambiental, paisajes, biodiversidad, otras). Por lo que es necesario desarrollar programas de actividades recreativas al aire libre como: deportivas, culturales y de educación ambiental que respondan a las necesidades y gustos de los visitantes, lo cual permitiría incrementar el interés turístico local y regional (Iazzetta, 2002). Algunos estudios de recreación han establecido que el uso y la percepción de los espacios recreativos citadinos está en función de las diferentes realidades socioeconómicas o sociodemográficas: rango etario, sexo, educación, lugar de residencia e ingreso de las personas que hacen uso de ellos (Casals y Olivares, 1999; Payne, et al., 2002; Sasidharan, et al., 2005). Esta hipótesis puede ser contrastada a través de dos enfoques teóricos:

1. Enfoque de la psicología ambiental y de geografía de la percepción. Estas perspectivas permitirían determinar, comprender y analizar los componentes socioeconómicos significativos en la percepción que tienen los individuos de la imagen citadina y por lo tanto del uso de los espacios recreativos. Además de que tales perspectivas permiten analizar la interrelación del comportamiento humano y el marco ambiental de espacios recreativos ambientales (Casals y Olivares, 1999). Este último punto está en relación con el tema de justicia ambiental y espacios públicos, el cual sugiere que las personas con bajos niveles de ingreso o en situación vulnerable (gente pobre o discriminada) tienen menor acceso a actividades recreativas como deporte en espacios verdes urbanos (Abercrombie, et al., 2008; Taylor, et al., 2006). Por lo mismo, es fundamental contrastar como hipótesis, la forma en que se relaciona el perfil sociodemográfico con el uso, calidad y características de los espacios recreativos citadinos. Entre los estudios de psicología ambiental y de geografía de percepción elaborados en parques urbanos, destaca el trabajo de Payne, et al. (2002) al determinar preferencia por tipo de recreación y de necesidades de superficie verde a través de modelos logísticos. Empleando técnicas de análisis multivariado, Sasidharan, et al., (2005), analizan gustos recreativos y preferencias de visita en función de etnia y variables sociodemográficas como sexo, educación e ingreso.

2. Enfoque económico. Esta perspectiva parte de la teoría de la demanda de Lancaster que determina que los consumidores de bienes derivan utilidad de los atributos que tienen los bienes, más que obtenerla de manera directa. Esta teoría se ha extendido a estudios económicos de bienes públicos de importancia recreativa/ambiental como las investigaciones de Bengochea, et al. (2007) y Dumitras y Dragoi (2007). De acuerdo a Arcarons y Calonge (2008), bajo una perspectiva económica se pueden derivar econométricamente diversos modelos de demanda de acuerdo al tipo de variables explicativas del uso del bien, por ejemplo:

- Modelos multinomiales (incluyen sólo variables socioeconómicas);

- modelos condicionales (incluyen sólo variables que explican los atributos del bien) y

- modelos mixtos (comprenden variables socioeconómicas y variables de atributos). Los últimos dos tipos de modelos (condicionales y mixtos) permitirían analizar la demanda del bien bajo la perspectiva propuesta por Lancaster.

De esta forma, los modelos de uso de bienes se han extendido a estudios de recreación en parques urbanos considerando demanda de visitas recreativas en función de atributos del parque y perfil sociodemográfico del visitante; por ejemplo a través de modelos logits mixtos (Kemperman y Timmermans, 2006). También se han desarrollado modelos gravitacionales que analizan la frecuencia de visitas a parques en función de las distancias y de las cualidades o atributos de los espacios (Stynes, et al., 1985; Cho, 1993; De Frutos, 2004). Consecuentemente, diversos estudios han encontrado relaciones estadísticas significativas entre el perfil sociodemográfico (sexo, edad, educación) con días de visita, tiempo de visita, frecuencia de uso y actividades recreativas (Sasidharan, et al., 2005) e igual entre ingreso y frecuencias de uso (Abercrombie, et al., 2008). Por mencionar ejemplos específicos:

1. Trabajos en Estados Unidos citan que: la frecuencia de uso disminuye con respecto a la edad (Payne, et al., 2002), mientras que en otros se incrementa (Kemperman y Timmermans, 2006). Igualmente se ha mencionado que personas de menores ingresos tienen una menor accesibilidad a espacios recreativos y por lo tanto menor participación recreativa de ese grupo (Taylor, et al., 2006).

2. Mientras que en países como Turquía se ha encontrado que las preferencias por parques recreativos están relacionadas con el estado civil de la persona (casada o soltera) con una intensidad de uso que disminuye con la edad a partir del rango etario de 19-24 y si el usuario es mujer (Oguz, 2000; Yilmaz, et al., 2007).

Las investigaciones que intentan analizar y contrastar hipótesis sobre recreación en México, son escasas desde las perspectivas de análisis de psicología ambiental, de percepción y de tipo económico, junto con el desarrollo de modelos que la expliquen. Recientemente, Flores-Xoloco- 
tzi (2011), encontró que para un parque de la Ciudad de México, diversas variables sociodemográficas como sexo, edad, educación e ingreso mensual familiar están relacionadas significativamente con frecuencia de uso, días de visita, horarios de visita y elección de actividades recreativas en el espacio verde. Con relación a las métodos estadísticos empleados, Payne, et al., (2002) y Kemperman y Timmermans (2006) han abordado el estudio de recreación en parques, a través de regresiones logísticas; también mediante la aplicación de técnicas como el análisis multivariado de la varianza (Sasidharan et al., 2005) y en ocasiones correlaciones canónicas lineales y no lineales para analizar recreación y evaluar el impacto ambiental de actividades humanas en parques urbanos (FloresXolocotzi, 2011; Hammit, et al., 1996). Llama la atención que tales técnicas son empleadas comúnmente en epidemiología y mercadotecnia, pero se han aplicado poco en el análisis de gustos y preferencias de bienes públicos como los parques. Por lo mismo, es necesario hacer uso de tales técnicas, considerando que la recreación en espacios públicos comprende múltiples variables como gustos recreativos (deporte, actividades de relajación, contemplar la naturaleza, pasear con la familia, convivir con amistades; otras), preferencias de visita (frecuencia de uso, horarios, días de visita, acudir solo o acompañado), aspectos sociodemográficos (sexo, nivel escolar, ingreso familiar, entre otros). Considerando lo anterior, esta investigación tiene como objetivo general estudiar la recreación en el Parque Ambiental Bicentenario de Metepec, Estado de México, desde una perspectiva social a través del análisis estadístico de información proveniente de encuestas aplicadas in situ. Para lograr lo anterior, este estudio, seguirá la línea teórica de geografía de la percepción y psicología ambiental como el estudio de Payne, et al. (2002), considerando modelos logits multinomiales (Arcarons y Calonge, 2008) que comprenden únicamente variables sociodemográficas, además de técnicas de análisis multivariado. Por lo tanto, el análisis se dividirá en los siguientes objetivos particulares:

1. Describir la relación entre el perfil sociodemográfico de los visitantes (sexo, edad, educación, residencia, ingreso familiar, si el visitante tiene hijos que lleve al parque) con los gustos recreativos y preferencias de visita realizada (frecuencia, horarios y días de visita).

2. Determinar que variables del perfil sociodemográfico (sexo, edad, educación, residencia, ingreso familiar, si el visitante tiene hijos que lleve al parque) son estadísticamente significativas en la elección de gustos recreativos y preferencias de visita realizada (frecuencia, horarios y días de visita).

3. Determinar de manera general, la percepción de los visitantes del Parque sobre: calidad del espacio y servicios recreativos que se realizan (educación ambiental, deporte y actividades familiares).

4. Proponer algunas sugerencias y recomendaciones que contribuyan a generar un programa de servicios recreativos que proporcione el Parque Ambiental Bicentenario.

\section{Descripción del área de estudio}

El Parque Ambiental Bicentenario se encuentra en el Municipio de Metepec, perteneciente al Estado de México, el cual de acuerdo a Instituto Nacional de Estadística Geografía e Informática (INEGI, 2004) forma parte de la Zona Metropolitana de la Ciudad de Toluca (ZMCT). La ZMCT tiene una superficie de $1,991.0 \mathrm{~km}^{2}$ y la integran los municipios de Almoloya de Juárez, Calimaya, Chapultepec, Lerma, Metepec, Mexicaltzingo, Ocoyoacac, Otzolotepec, San Mateo Atenco, Toluca, Xonacatlán y Zinancatepec (INEGI, 2004). Según el conteo de población y vivienda 2005, la población de esta zona asciende a un total de 1,361,500 habitantes (INEGI, 2008). En cuanto al municipio de Metepec, tiene una superficie de $69 \mathrm{~km} 2$ con una población hacia 2005 de 206,005 habitantes (INEGI, 2008). De acuerdo al Plan Municipal de Desarrollo de Metepec (Gobierno Municipal de Metepec, 2008), se señala que el municipio tiene inventariado los siguientes tipos de áreas verdes urbanas dentro del subsistema recreativo (clasificación propuesta por SEDESOL, 1999), los elementos verdes son: 11 juegos infantiles, 12 jardines vecinales, 14 parques de barrio y 7 Parques Urbanos. El Parque Ambiental Bicentenario es de reciente inauguración. Surgió a través de un reclamo ciudadano en el año 2009 por dotar de más áreas verdes de libre acceso al municipio. El diseño del parque comprendió las siguientes características: espacio bardeado, con acceso controlado, de 104 ha, dirigido a las familias en general con tres funciones principales de uso: educación ambiental infantil; promover recreación familiar; junto con equipamiento y espacios diseñados para la práctica del deporte. El costo total del proyecto requirió una inversión de 700 millones de pesos, los costos a detalle de la planificación y diseño son descritos por Sánchez-Gasca (2009). El horario de acceso al parque es de 6 am a 6 pm con vigilantes en los accesos y vigilantes que recorren el espacio a lo largo del día. Las actividades de educación ambiental, están programadas en el Museo del Niño; están especialmente dirigidas a niños en edad de 4 a 12 años, a través de actividades lúdicas dirigidas fortalecer la conciencia ambiental y la importancia de la conservación de los ecosistemas.

El Plan de Diseño Arquitectónico del parque se ejecutó en tres fases, consecuentemente, tales espacios se abrieron paulatinamente al público de la siguiente forma:

- Primera fase. En junio de 2009, se inauguraron 30 ha del Parque, con los siguientes servicios: "Papalote $\mathrm{Mu}$ seo del Niño (centro de educación ambiental infantil"; cuerpo de agua; trotapista de $3 \mathrm{~km}$; ciclopista de 1.1. $\mathrm{km}$; estacionamiento con capacidad de 532 vehículos; cerca perimetral; equipamiento de material plástico equivalente a 400 toneladas de material reciclado; dos módulos de baños. El parque cuenta sólo con dos entradas: una ubicada en Avenida México y una entrada secundaría en la Avenida Tecnológico (Figura 1). En esta fase, se tuvo un promedio de 13 mil visitantes a la semana (Sánchez-Gasca, 2009).

- Segunda fase. En junio de 2010 se incorporaron, 18 
hectáreas: áreas deportivas (canchas de basquetbol, 2 canchas de futbol), kioscos para venta de alimentos y áreas de convivencia familiar.

- Tercera fase. Fecha no definida. Se incorporará, el resto de superficie principalmente para conservación forestal.
Por lo tanto, y considerando las recomendaciones de Oguz (2001) y Chiesura (2004), se diseñó una encuesta dirigida a visitantes del parque de 15 años en adelante, y que acostumbren visitar el parque. El objetivo de la encuesta fue: conocer el perfil socioeconómico de los visitantes (sexo, ingreso mensual familiar, lugar de residencia,

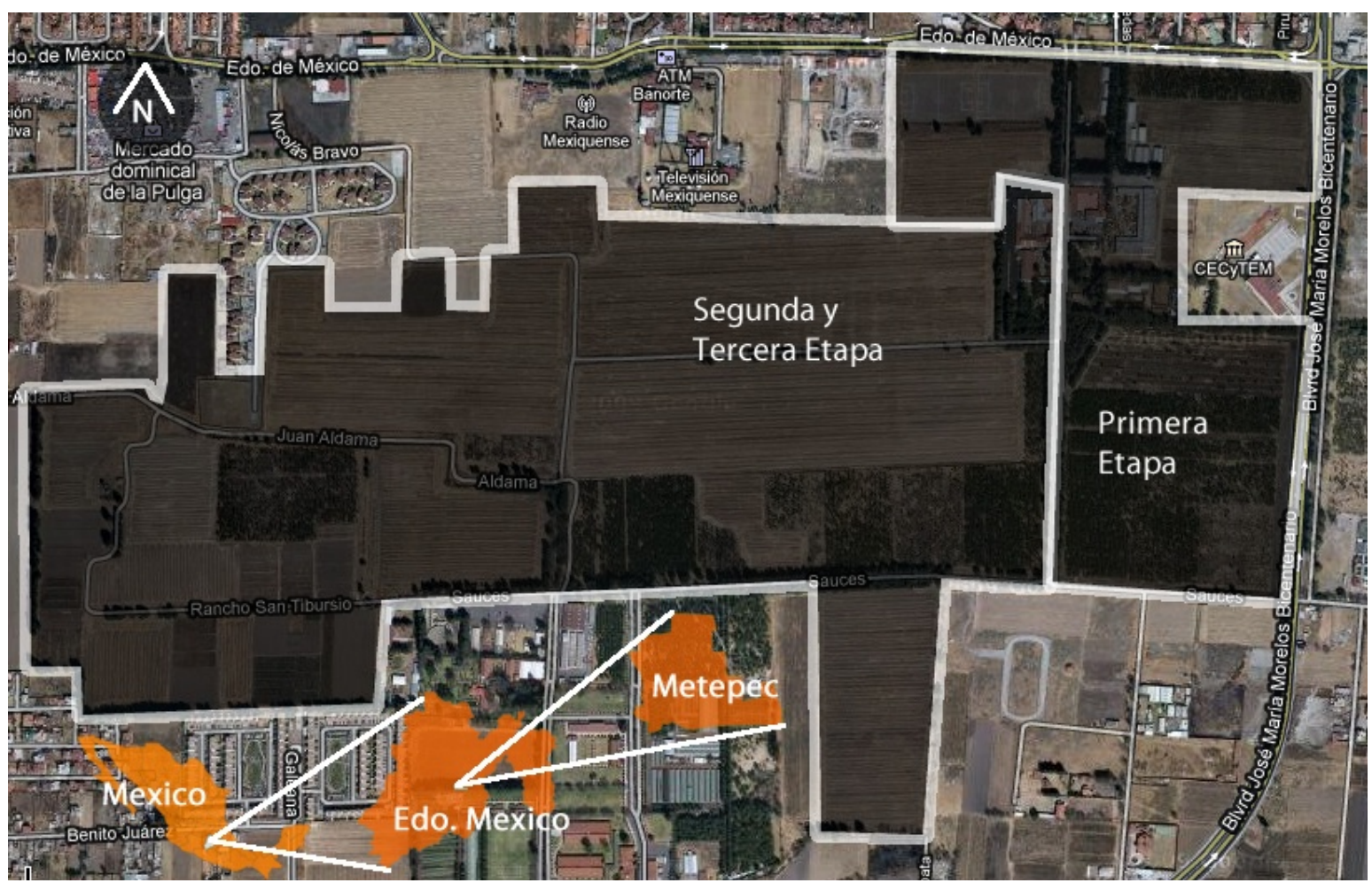

Figura 1. Mapa que indica la ubicación del Parque Ambiental Bicentenario. Fuente: Google Inc., 2010

\section{Metodología}

Considerando la teoría de geografía de la percepción y psicología ambiental, la metodología que se desarrolló consideró como hipótesis de trabajo que: a) existe una relación entre el perfil sociodemográfico de los visitantes (sexo, edad, educación, residencia, ingreso familiar, si el visitante tiene hijos que lleve al parque) con los gustos recreativos y con las preferencia visita realizada, tal como se ha observado en algunas investigaciones (Flores-Xolocotzi, 2011; Sasidharan, 2005); b) variables sociodemográficas como: sexo, edad, educación, ingreso, otras son estadísticamente significativas en la elección de gustos recreativos y preferencias de visita como se observa en Payne et al. (2002); Kemperman y Timmermans, (2006) y Flores-Xolocotzi (2011); c) aunque los visitantes que acuden el parque consideran buena la calidad del parque, ellos mismo identifican problemas dentro del espacio y que debieran ser atendidos por la administración del parque y d) considerando lo anterior, se pueden emitir recomendaciones que permitan satisfacer las necesidades, gustos y perspectivas del visitante. escolaridad, número de personas que integran su familia); los gustos recreativos; además de averiguar las percepciones y expectativas que los visitantes tienen sobre el parque en aspectos como: calidad del espacio y problemas dentro del espacio. Un bloque de las preguntas consistió en obtener el valor económico del servicio recreativo y cuyos resultados y análisis forman de parte de otra investigación que se realizó paralelamente a la que se presenta en este trabajo. Antes de levantar en campo las encuestas, se realizó una fase de validación que consistió en aplicar la encuesta a 20 visitantes, esta fase permitió:

- Calibrar la encuesta. Consistió en medir el tiempo de aplicación y, en verificar si la redacción de las preguntas era la adecuada.

- Esquema de muestreo. Se emplearon datos premuéstrales de ingreso mensual familiar, para estimar un tamaño de muestra completamente al azar para la encuestas que se van a levantar en campo. Se seleccionó la variable ingreso, por la relación que tiene esta variable con los niveles socioeconómicos de la Asociación Mexicana de Agencias de Investigación de Mercado y Opinión Pública A.C. (AMAI, 2006), además de la posible relación que pudiera tener esta variable en la 
elección de gustos y preferencias recreativas (Oguz, 2000). La fórmula empleada para estimar tamaño de muestra, de acuerdo a lo recomendado por Santos, et al., (2003), fue:

$$
\mathrm{n}=\frac{\mathrm{z}_{1-\infty}^{2} \times / 2}{\mathrm{~d}^{2}}
$$

Donde:

$n=$ tamaño de la muestra.

$d=$ error aceptable o precisión.

$S^{2}$ = varianza del ingreso mensual familiar, estimada con los resultados de la premuestra de 20 visitantes del parque.

$Z_{1-a / 2}=$ es la desviación estándar, la cual considera la distribución " $t$ " con $n-1$ y que corresponde en tablas a $Z_{0.975}=1.96$.

1- $a=$ nivel de confianza.

Después de hacer un análisis de sensibilidad con determinados niveles de precisión y significancia, aunado al costo de aplicación, se seleccionó una muestra $(n)$ de 184, con una precisión absoluta de 0.12 y nivel de confianza de $97 \%$. Las encuestas se aplicaron de octubre de 2009 a enero de 2010 dentro del parque previa autorización de los administradores; entre semana y fines de semana; en las mañanas y en las tardes y de forma voluntaria a personas que aceptaron ser encuestadas.

Considerando los objetivos de esta investigación y los resultados de la prueba piloto, se tomó la decisión de no encuestar a visitantes que acudan por primera vez al parque, debido a que tienden a desconocer los servicios que presta el espacio, e igual no tienen gustos recreativos que hayan practicado en el parque ni preferencias de visitas definidas.

Los resultados de las encuestas se emplearon para describir el perfil socioeconómico del visitante; posteriormente se generaron modelos sociales del servicio recreativo, de la siguiente forma:

1. Considerando las características del parque se aplicaron las siguientes técnicas estadísticas:

a) Todas las variables se categorizaron, en el caso de la edad se emplearon los rangos etarios sugeridos por Vera (2005) para estudiar gustos recreativos en función de la edad: 15-18 años, 19 a 30 años, 31 a 55 años, más de 55 años.

b) Para categorizar el ingreso mensual familiar, se empleó la clasificación de la Asociación Mexicana de Agencias de Investigación de Mercado y Opinión Pública A.C. (AMAI, 2006), que permite diferenciar cada intervalo de ingreso familiar por nivel socioeconómico. Las características a detalle de cada nivel son descritos en López (2009). La clasificación de la AMAI consta de las siguientes categorías o niveles socioeconómicos:

- Nivel C+. El ingreso asociado de esta categoría es de $\$ 35,000$ a 84,999 . Es el segundo estrato con el más alto nivel de ingresos del país (el estrato A/B más de 85 mil pesos no se encontró entre los visitantes del parque); Representa al
13.7 \% de la población del país.

- Nivel C. Con un ingreso de $\$ 11,600$ a $\$ 34,999$. A Este nivel se denomina regularmente como medio. Representa al 17 \% de la población nacional.

- Nivel D+. Es el nivel más grande y representativo de la población (36.4\%).

- Nivel D. Ingreso familiar de $\$ 2,700$ a $\$ 6,799$. Este nivel es el segundo más pobre de la población (15\%).

- Nivel E. Tiene un ingreso de $\$ 0$ a $\$ 2,699$. Es el nivel más pobre, representa a $10 \%$ de la población.

c) Por su parte, educación se categorizó en educación básica (comprendía haber cursado algún grado de primaria y/o secundaria en un rango que va de 1 a 9 años de educación), educación media (algún grado de bachillerato que va de una rango de 10 a 12 años de educación) y educación superior (algún período de licenciatura o más, en un rango que va de 13 años de educación en adelante).

d) Para describir la relación entre variables sociodemográficas, gustos recreativos y preferencias de visita, se elaboró un modelo social recreativo con tres conjuntos de variables: a) socioeconómicas; b) tipo de visita y c) gustos/preferencias recreativas. La lista de variables en cada conjunto se describe posteriormente. Para realizar el análisis del modelo se empleó una correlación canónica no lineal (CCNL) en SPSS versión 19. Se optó por un análisis no lineal en lugar del lineal empleado por Hammit, et al., (1996), debido a que la CCNL permite describir simultáneamente la relación existente entre más de dos conjuntos de variables, tal como lo sugieren Golob y Regan (2002); Meulman y Heiser (2007) y Yazici, et al., (2010) para modelos con dos o más conjuntos de variables categóricas. Para obtener el ajuste final, se realizó un análisis de sensibilidad, analizando: a) diferentes tipos de escalamiento (ordinal o nominal en cada variable) y b) los valores de ajuste obtenidos ante cambios en los escalamientos, tal como lo sugieren Meulman y Heiser (2007).

e) Posteriormente, se realizaron regresiones logísticas para determinar si existe alguna relación estadística significativa entre las actividades recreativas y preferencias de visita de los usuarios, en función de las siguientes variables sociodemográficas: sexo, edad, educación, ingreso mensual familiar, lugar de residencia, además de si el visitante tiene hijos a los que lleve al parque; tal como lo sugiere Payne, et al., (2002). Las categorías base de las variables independientes fueron respectivamente: mujer; edad 15 a 18 años; educación básica; nivel de ingreso E (de la AMAI); residencia fuera del Municipio de Metepec y no tiene hijos que lleve a pasear al parque. Las regresiones se realizaron en SAS versión 9.1 de acuerdo a lo recomendado por Agresti 
(2007). Para obtener los mejores modelos: el nivel mínimo de significancia de las variables independientes se fijó en 0.1. Las variables dependientes de los modelos fueron:

- Cuatro variables de gustos recreativos (modelos binarios): deporte, actividades recreativas familiares, relajación y participar en las actividades de educación ambiental infantil (en la cual los visitantes llevan/acompañan a niñas/ niños que participen en dichas actividades). Se escogieron estas variables ya que su frecuencia de respuesta superior al $20 \%$, evitó celdas con cero en las matrices de datos categóricos.

- Tres variables de tipo de visita: Frecuencia de visita (modelo ordinal), horario preferido de visita (modelo nominal) y día preferido de visita (modelo nominal). Se excluyó del análisis la variable de preferencia "Acude al parque sólo o acompañado", debido a que la tasa de visitantes que prefieren acudir solos fue únicamente de $9 \%$, dificultando de esta forma la obtención y ajuste de un modelo logístico.

2. Posteriormente, se realizó un análisis de las percepciones que el usuario tiene sobre el espacio (calidad del espacio y administración) y las actividades que se realizan como educación ambiental, deporte y actividades familiares.

\section{Resultados generales de la muestra}

Considerando la muestra encuestada ( $\mathrm{n}=184) ; 39.1 \%$ de la población de visitantes está constituida por mujeres y $60.9 \%$ de hombres. El promedio de edad, ingreso y escolaridad de visitantes de 15 años en adelante, es respectivamente de: 36.5 años de edad (desviación estándar=13.1) y $\$ 13,852.4$ (desviación estándar=12,147.7); 14.2 años de educación (desviación estándar=3.6). Además, se obtuvo que el $54.4 \%$ del total de visitantes tienen hijos con los que acuden a visitar el parque. Los porcentajes por categoría de ingreso, edad y escolaridad están en la Tabla 1.

En cuanto a lugar de residencia de los visitantes, se encontró que un $54.6 \%$ de ellos viven en el municipio de Metepec y el porcentaje restante fuera de Metepec. Los porcentajes de lugar de residencia de otros municipios

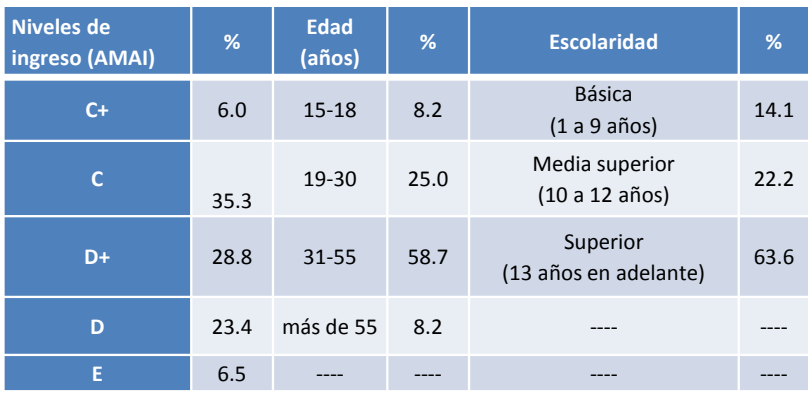

Tabla 1. Ingreso, edad, y escolaridad de los visitantes del parque. Fuente: elaboración propia a partir de trabajo de campo.

mexiquenses y otras entidades de México aparecen en la Tabla 2.

Hay que destacar que los resultados hasta este punto, indican que el parque es visitado principalmente por gente procedente de Metepec, que se caracterizan por tener educación superior, pertenecer al nivel socioeconómico $\mathrm{C}$ de la AMAI (rango de ingresos de $\$ 11,600$ a $\$ 34,999$ ) y en donde poco más de la mitad de la población de visitantes tiene hijos a los que lleva a visitar al espacio verde.

\section{Resultados y análisis de los gustos y preferencias recreativas}

Con respecto a actividades recreativas se encontró que los visitantes acuden al parque, realizan: deporte (83.7 $\%$ ); actividades recreativas familiares (jugar con los hijos, paseo y convivencia familiar) (51.1\%); actividades de relajación (33.3\%); actividades de educación ambiental dirigidas a niños (20.6\%); el resto de actividades recreativas se puede consultar en la Tabla 3. En cuanto al orden de preferencias de las actividades recreativas reportadas, el porcentaje de visitantes que establecieron en el primer lugar de sus preferencias a deporte, actividades familiares, actividades de relajación y educación ambiental, fueron respectivamente de: $77.3 \% ; 46.8 \% ; 17.7 \%$ y $18.4 \%$. El orden de preferencias restantes, considerando todas las actividades recreativas está en la Tabla 3 . Se observa que predominan en los gustos: actividades deportivas y actividades de recreación familiar. Lo cual coincide con dos de las funciones principales para las cuales se diseñó el espacio: deporte y recreación familiar. Sin embargo, el servicio de educación ambiental que se presta en las instalaciones del parque es reportado con menor frecuencia por la población de visitantes con respecto

\begin{tabular}{|c|c|c|c|c|c|}
\hline $\begin{array}{l}\text { Estado de } \\
\text { México }\end{array}$ & $\%$ & Otros Municipios de Estado de México & $\%$ & Otras entidades & $\%$ \\
\hline Metepec & 54.6 & Naucalpan & 1.6 & Distrito Federal & 3.3 \\
\hline Toluca & 26.8 & San Felipe del Progreso & 1.6 & \multirow{3}{*}{$\begin{array}{c}\text { Otros (Michoacán, } \\
\text { Puebla, Tamaulipas, } \\
\text { Jalisco, Morelos; } \\
\text { Veracruz) }\end{array}$} & \multirow{3}{*}{2.2} \\
\hline $\begin{array}{c}\text { San Mateo } \\
\text { Atenco }\end{array}$ & 4.4 & Lerma & 1.1 & & \\
\hline Calimaya & 2.2 & $\begin{array}{l}\text { Santiago Tianquistengo; Nicolás Romero; } \\
\text { Cuautitlán Izcalli; Tenango del Aire }\end{array}$ & 2.2 & & \\
\hline Total & 88 & & 6.5 & & 5.5 \\
\hline
\end{tabular}
a deporte, relajación y recreación familiar, e igualmente se observa que su grado de importancia es menor si se compara con las actividades señaladas anteriormente.

En cuanto a los resultados de frecuencia de visita, horario de visita y días de visita, estos se encuentran en la Tabla 4. Además se obtuvo que el $94.4 \%$ de los visitantes prefieren acudir acompañados al parque.

Tabla 2. Lugar de residencia de los visitantes del Parque. Fuente: Elaboración propia a partir de trabajo de campo. 


\begin{tabular}{|c|c|c|c|c|c|c|c|c|}
\hline \multirow[b]{2}{*}{ Actividad recreativa } & \multirow{2}{*}{$\begin{array}{c}\% \\
\text { poblaciona } \\
\text { I } \\
\text { que realiza } \\
\text { la actividad }\end{array}$} & \multicolumn{7}{|c|}{$\begin{array}{l}\% \text { en orden preferencial con respecto al total de personas } \\
\text { que mencionaron la actividad }\end{array}$} \\
\hline & & $\begin{array}{l}\text { Primer } \\
\text { lugar }\end{array}$ & $\begin{array}{l}\text { Segund } \\
\text { o lugar }\end{array}$ & $\begin{array}{l}\text { Tercer } \\
\text { lugar }\end{array}$ & $\begin{array}{l}\text { Cuart } \\
\text { o } \\
\text { lugar }\end{array}$ & $\begin{array}{l}\text { Quint } \\
\text { o } \\
\text { lugar }\end{array}$ & $\begin{array}{l}\text { Sexto } \\
\text { lugar }\end{array}$ & $\begin{array}{l}\text { Séptim } \\
\text { o lugar }\end{array}$ \\
\hline Deporte & 83.7 & 77.3 & 16.9 & 4.5 & ------- & 0.6 & 0.6 & ------- \\
\hline Relajación & 33.7 & 17.7 & 53.22 & 22.6 & 3.2 & 3.2 & ------- & ------- \\
\hline Ver el paisaje & 15.8 & 6.9 & 31 & 27.6 & 31 & 3.4 & ------- & ------- \\
\hline $\begin{array}{l}\text { Pasear y convivir con } \\
\text { familia }\end{array}$ & 51.1 & 46.8 & 30.9 & 9.6 & 7.4 & 2.1 & 3.2 & \\
\hline $\begin{array}{c}\text { Actividades de } \\
\text { educación ambiental } \\
\text { dirigidas a niños } \\
\text { (acompañamiento) }\end{array}$ & 20.7 & 18.4 & 34.2 & 21.1 & & 10.5 & 7.8 & 7.9 \\
\hline Consumir alimento & 13 & ------ & 29.2 & 16.7 & 12.5 & ------- & 8.3 & 8.3 \\
\hline $\begin{array}{c}\text { Otras (platicar, leer, } \\
\text { distraerse con un } \\
\text { juguete }\end{array}$ & 14.1 & 7.7 & 38.5 & 15.4 & 7.7 & 3.8 & 7.7 & 19.2 \\
\hline
\end{tabular}

Tabla 3. Gustos y preferencias recreativas en el parque. Fuente: Elaboración propia a partir de trabajo de campo.

\begin{tabular}{|c|c|c|c|c|c|}
\hline Frecuencia de visita & $\%$ & Horario de visita & $\%$ & Día de visita & $\%$ \\
\hline 1 a 5 veces al mes & 42.4 & $\begin{array}{c}\text { Desde que abren } \\
\text { hasta } 12 \mathrm{pm}\end{array}$ & 51.6 & Entre semana & 19.6 \\
\hline Más de 5 veces al mes & 38.6 & Después de las $12 \mathrm{pm}$ & 33.1 & $\begin{array}{l}\text { Fines de semana } \\
\text { (sábado/domingo } \\
\text { ) }\end{array}$ & 50 \\
\hline No acostumbra visitarlo & 19 & $\begin{array}{c}\text { Sin preferencia de } \\
\text { horario }\end{array}$ & 15.2 & $\begin{array}{c}\text { Sin preferencia } \\
\text { de día }\end{array}$ & 30.4 \\
\hline
\end{tabular}

Tabla 4. Frecuencia, horario y días de visita preferidos por los usuarios del parque. Fuente: Elaboración propia con datos obtenidos en campo.

\section{Relación entre variables sociodemográficas, gustos recreativos y preferencias de la visita}

El ACCNL permitió describir y analizar, la relación entre los siguientes tres conjuntos de variables que describen la recreación dentro del parque:

a) Sociodemográficas: sexo; edad; nivel educativo; ingreso mensual familiar; si el entrevistado tiene hijos a los que lleve al parque y lugar de residencia.

b) Gustos recreativos: Para este análisis, las actividades recreativas incluidas fueron: practicar algún deporte (ciclismo, trote, caminar, patear la pelota, patinaje, otros) ver el paisaje, actividades recreativas familiares (estar con los hijos, llevar a los niños los juegos infantiles y pasear con la familia); relajación, actividades de educación ambiental (en donde los padres u otras personas mayores acompañan a los niños a esas actividades), comer dentro del parque (aunque pudiera pensarse que es una actividad familiar, la realidad es que las personas que comentaron que comían dentro del espacio, no lo consideraban así, ya que comían solas, con amistades, o compañeros de la escuela/trabajo), además de otras actividades (leer, platicar, jugar con coches, aviones o barcos de juguete (este tipo de juegos se reportaron como realizados por personas adultas).

c) Preferencias de visita (Tipo de visita). Frecuencia de visita, horario preferido de visita, días preferidos de visita y si la persona prefiere acudir sola o acompañada.

El modelo de CCNL que obtuvo el mejor nivel de ajuste aparece en la Tabla 5. En éste se observa que a excepción de la variable educación (escala ordinal), el resto se escaló como variables nominales simples en dos dimensiones, de acuerdo al análisis de sensibilidad realizado ante cambios en los escalamientos, tal como lo recomiendan Golob y Regan (2002) y Meulman y Heiser (2007). El nivel de ajuste alcanzado es de 1.145 de un valor máximo posible de dos, el cual puede ser considerado como moderado (el mismo poder de ajuste indicarían los autovalores de cada dimensión considerando un valor máximo de uno). Estos resultados, están en el rango de valores obtenidos en otros estudios de correlación canónica no lineal en análisis de mercados (Guerrero, et al., 2009) y en epidemiología (Yazici, et al., 2010).

El análisis individual de las variables en cada conjunto, puede ser analizado considerando las saturaciones (cargas canónicas no lineales) de las variables en las dos dimensiones bajo las que se realizó la CCNL. De acuerdo a Garrido y Polo (2002) se tomarán como significativas to-

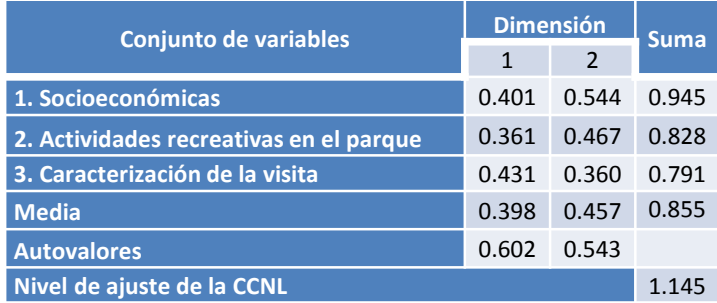

Tabla 5. Ajuste de la CCNL. Fuente: Elaboración propia a partir de trabajo de campo.

das aquellas variables con saturaciones superiores a 0.4 (en valor absoluto) en cualquiera de las dos dimensiones (Tabla 6). Consecuentemente, y de acuerdo a la contribución de cada variable en los 3 conjuntos (mayor peso), representada por el valor de saturación, se establece lo siguiente:

Dimensión 1. Considerando el fenómeno recreativo como un todo esta se explica particularmente en la parte sociodemográfica por: edad y si tiene hijos a los que lleve al parque. En el conjunto de gustos recreativos sobresalen actividades de relajación y comer alimentos. Mientras que en el tercer conjunto (preferencia de visita) destacan días preferidos. 
Dimensión 2. Aquí sobresalen en el conjunto de actividades recreativas: las actividades familiares y realizar actividades como leer, platicar y jugar (por ejemplo barcos de juguete en el espejo de agua). Por último en el conjunto de preferencias de visita son importantes la frecuencia de visita y horario preferido.

Estos resultados ponen de manifiesto la importancia de las actividades recreativas familiares dentro del parque, en las cuales estar con los hijos o llevarlos a los juegos, relajación y comer alimentos son variables importantes. Siendo también destacables las tres variables de preferencias de visita.

El comportamiento de las saturaciones se observa en el Gráfico de las saturaciones en donde a mayor distancia del centro mayor contribución de la variable dentro de los conjuntos (Gráfico 1).

Este análisis, se particulariza observando el gráfico del centroide (Gráfico 2), que comprende las categorías de cada variable. En este gráfico las categorías más alejadas del centro representan aquellas con bajas tasas de frecuencia. De esta forma, se pueden crear "agrupaciones" (Yacizi, et al., 2010) que pueden ayudar a describir las relaciones existentes entre las categorías de los 3 conjuntos que describen el comportamiento recreativo del visitante. En el gráfico se encuentran señalados agrupaciones que describen aspectos de la recreación, para su interpretación y análisis se considerará a la figura dividida en 4 cuadrantes: cuadrante superior izquierdo, cuadrante inferior izquierdo, cuadrante superior derecho y cuadrante inferior derecho, en los cuales destacan las siguientes agrupaciones de variables:

a) Cuadrante superior izquierdo

- Parte superior. Visitantes, que prefieren acudir fines de semana, que llevan hijos al parque, que realizan actividades familiares, no practican deporte y van de una a cinco veces al mes.

- Parte inferior. Visitantes mujeres, que vienen fuera de Metepec, acuden acompañadas, con ingresos mensuales familiares de $\$ 11,600.0$ a $\$ 34,999.0$ y educación superior.

b) Cuadrante inferior izquierdo

El análisis de este cuadrante comprende el grupo de variables sociodemográficas: ingreso de $\$ 0$ a $\$ 2,699$; de edades entre 31 a 55 años; preferencia por ir en las mañanas. Además en cuestiones de actividades recreativas no realizan actividades de relajación; no consumen alimentos en el parque; no realizan actividades de educación ambiental; no ven el paisaje; tampoco realizan otras actividades como leer, platicar o jugar). Este perfil sociodemográfico, pudiera realizar alguna de las otras actividades recreativas como: deporte, actividades familiares o alguna otra que pudiera no haber sido captada por la encuesta. Sin embargo, dichas actividades no muestran una correlación de peso en dicho perfil sociodemográfico, tal como lo demuestra el análisis descriptivo de este gráfico. Será necesario que futuros estudios profundicen más en los hábitos recreativos de este grupo sociodemográfico que al me-

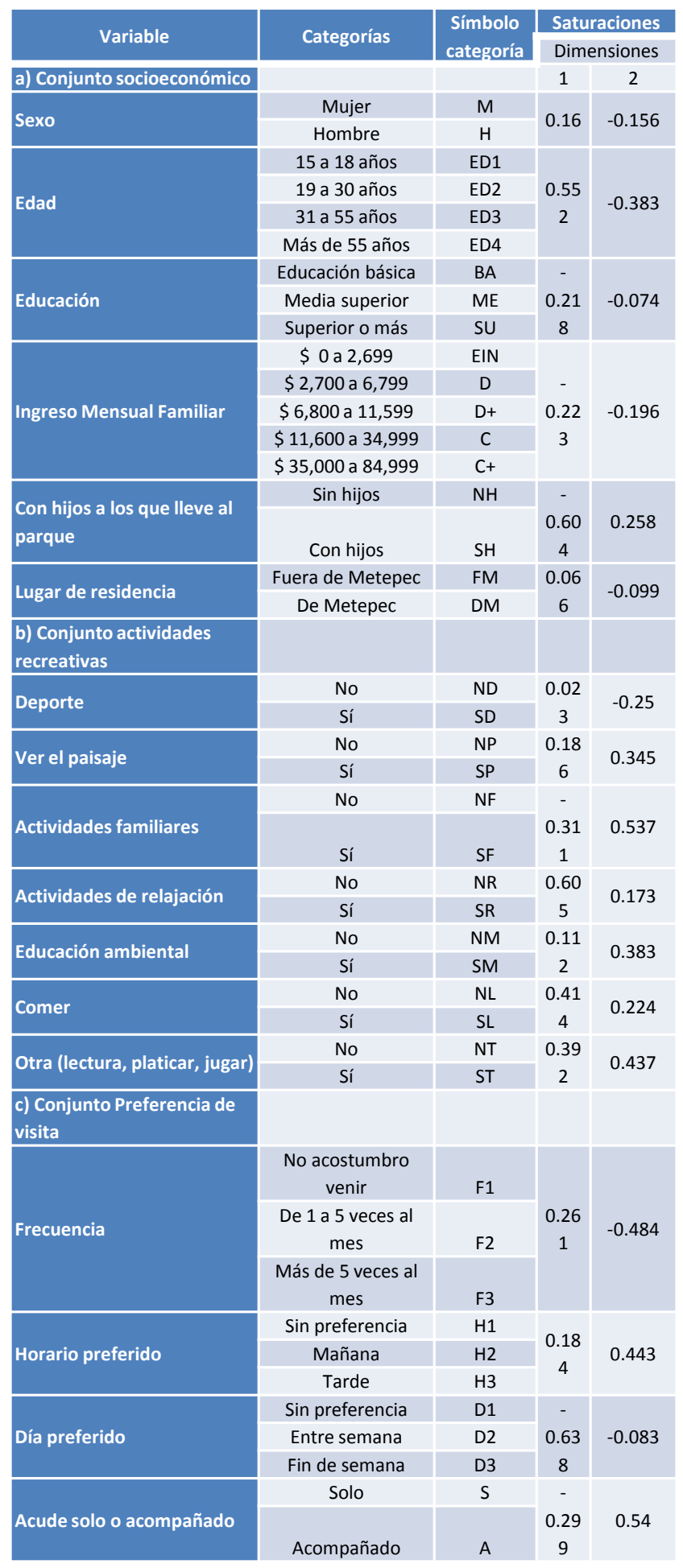

Tabla 6. Ponderaciones y saturaciones de cada variable. Fuente: Elaboración propia a partir de trabajo de campo. 


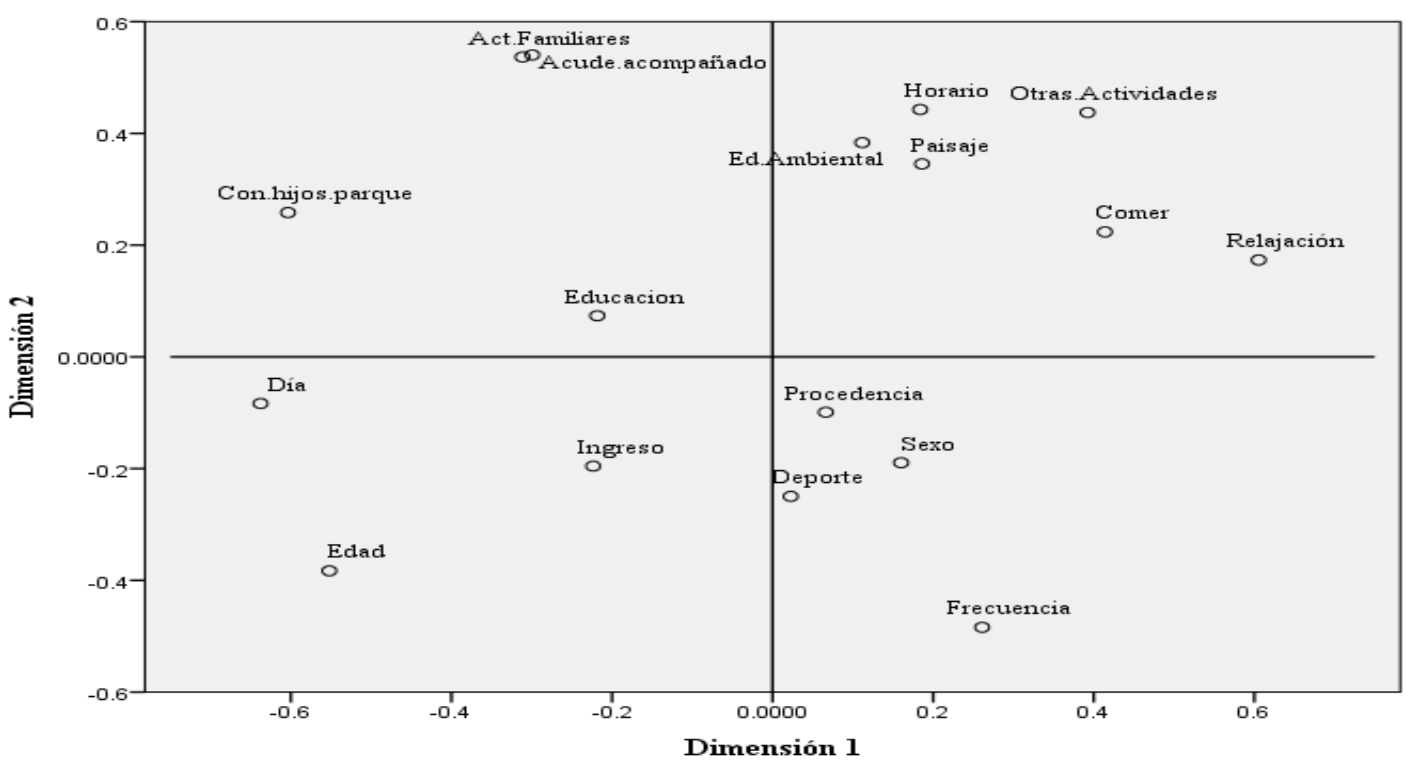

Gráfico 1. Saturaciones de las variables. Fuente: laboración propia a partir de trabajo de campo.

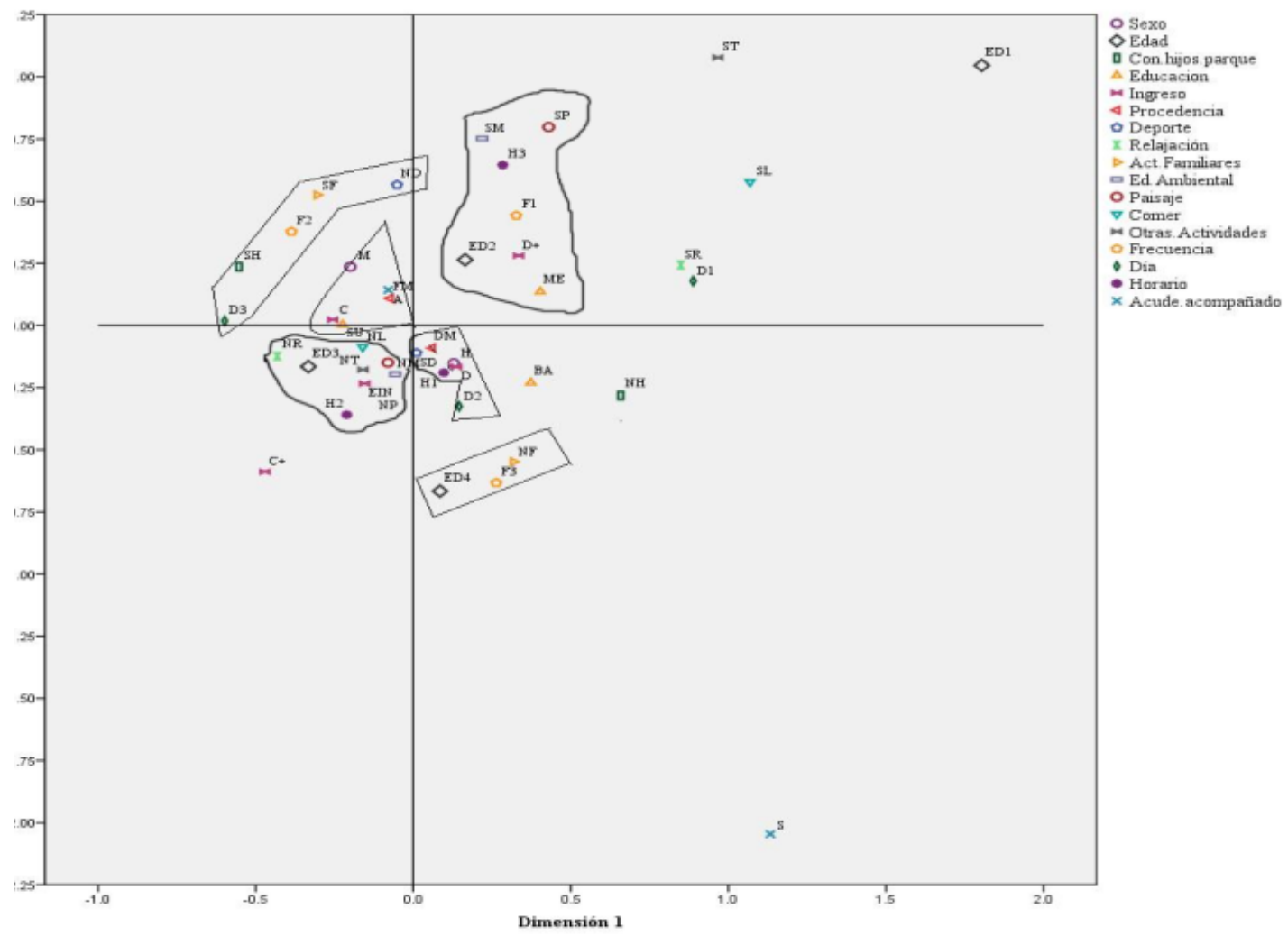

Gráfico 2. Centroide de las categorías de cada variable. Fuente: Elaboración propia a partir de trabajo de campo. 
nos en nivel de ingreso es el más pobre y por lo tanto en condiciones de vulnerabilidad.

c) Cuadrante superior derecho

En este cuadrante destaca el grupo de variables constituido por: personas en edad de 19 a 30 años; con niveles de ingreso de $\$ 6,800$ a $\$ 11,599$; con algún grado de educación media superior, que realizan actividades educación ambiental, acuden a ver el paisaje y que prefieren las visitas en la tarde pero no acostumbran visitar el parque.

d) Cuadrante inferior derecho

- Parte superior. Comprende a visitantes hombres, que no tienen preferencia por un horario (mañana o tarde), que prefieren acudir entre semana, que vienen de Metepec, que practican deporte y con un rango de ingreso de $\$ 2,700$ a $\$ 6,799$.

- Parte inferior. Es el grupo de visitantes de 55 años o más, que acuden más de 5 veces al mes y que no realizan actividades recreativas familiares, estas personas pudieran practicar otras actividades pero el análisis no demuestra alguna de peso.

Considerando lo anterior, una estrategia para promover un servicio recreativo incluyente, es promover las actividades deportivas en mujeres de diferentes niveles de ingreso y relacionar las actividades deportivas con actividades de recreación familiar, a través de la organización de eventos deportivos familiares. Sin embargo, no hay que olvidar que existe una función de educación ambiental infantil (acompañamiento de niños) que al parecer está siendo subutilizada en el parque. Este punto se abordará posteriormente.

\section{Modelos logísticos categóricos de recreación}

Los resultados de los modelos de gustos recreativos se encuentran en la Tabla 7. y los modelos de preferencia de visita en la Tabla 8. Los modelos estimados fueron significativos de la siguiente forma: a) modelo de deporte con valor de prueba de la razón de verosimilitud (LLR
$\left.\mathrm{Chi}^{2}\right)=8.07$ y nivel de significancia $(\mathrm{NS})=0.018$; b) modelo de actividades familiares $\mathrm{LLR} \mathrm{Chi}^{2}=8.68$ y NS=0.0032; c) modelo de relajación $\mathrm{LLR} \mathrm{Chi}^{2}=26.94$ y NS=0.0001; c) modelo de actividades de educación ambiental infantil (en donde los papás u otras personas mayores acompañan a los infantes) $\mathrm{LLR} \mathrm{Chi}^{2}=7.96$ y NS=0.047; d) modelo de frecuencia de visita con $\mathrm{LLR} \mathrm{Chi}^{2}=18.86$ y NS=0. 0008; e) modelo de horario preferido con LLR $\mathrm{Chi}^{2}=18.06$ y NS de 0.054; f) modelo de día preferido con $\mathrm{LLR} \mathrm{Chi}^{2}=35.69$ y NS de 0.0012 .

Los resultados de los modelos indican, los siguientes aspectos.

- La probabilidad de que el visitante realice actividades familiares se incrementa significativamente si tiene hijos a los que lleve al parque. Al respecto, Kemperman y Timmermans (2006) establecen a través de un análisis factorial que acompañar a los niños a las áreas de juego infantil son el factor principal de las actividades que realizan las familias en los parques urbanos holandeses.

- Aunque el deporte, sea la actividad más frecuente y favorita de los usuarios, la probabilidad de que sea realizada se incrementa significativamente si el visitante es de Metepec y particularmente en el rango de edad de 31 a 55 años con respecto a los que tienen entre 15 a 18 años. La significancia de la edad en modelos de elección de actividades recreativas como deporte coincide con los resultados de Payne et al., (2002) en Estados Unidos y Kemperman y Timmermans (2006) en Holanda. Sin embargo, mientras que los resultados de Payne et al. (2002), muestran que las categoría de adultos mayores (más de 50 años) realizan más actividades deportivas que las categorías de adultos jóvenes, la relación edad-deporte en Holanda muestra que la preferencia por actividades deportivas disminuye a medida que se incrementa la edad. Desafortunadamente, estudios poblacionales de preferencias recreativas como deporte considerando rangos de edad de visitantes en parques públicos de México, no están

\begin{tabular}{|c|c|c|c|c|c|c|c|c|c|c|c|c|c|c|c|}
\hline \multicolumn{4}{|c|}{$\begin{array}{l}\text { Modelo de deporte (base: no } \\
\text { realiza) }\end{array}$} & \multicolumn{4}{|c|}{$\begin{array}{l}\text { Modelo de relajación (base: no } \\
\text { realiza) }\end{array}$} & \multicolumn{4}{|c|}{$\begin{array}{l}\text { Modelo de actividad familiar (base: no } \\
\text { realiza) }\end{array}$} & \multicolumn{4}{|c|}{$\begin{array}{l}\text { Modelo de educación ambiental } \\
\text { (base: no realiza) }\end{array}$} \\
\hline Variable & $\beta$ & $\begin{array}{l}\text { Signifi- } \\
\text { cancia }\end{array}$ & $\begin{array}{l}\text { Odds } \\
\text { ratio }\end{array}$ & Variable & $\beta$ & $\begin{array}{c}\text { Signifi } \\
- \\
\text { cancia }\end{array}$ & $\begin{array}{l}\text { Odds } \\
\text { ratio }\end{array}$ & Variable & $\beta$ & $\begin{array}{l}\text { Signifi- } \\
\text { cancia }\end{array}$ & $\begin{array}{l}\text { Odds } \\
\text { ratio }\end{array}$ & Variable & $\beta$ & $\begin{array}{l}\text { Signifi- } \\
\text { cancia }\end{array}$ & $\begin{array}{l}\text { Odds } \\
\text { ratio }\end{array}$ \\
\hline $\begin{array}{l}\text { Inter- } \\
\text { cepto }\end{array}$ & $\begin{array}{c}0.8 \\
3\end{array}$ & 0.011 & & Inter-cepto & 0.93 & 0.041 & & Inter-cepto & -0.44 & 0.051 & & $\begin{array}{l}\text { Interce } \\
\text { pto }\end{array}$ & -0.5 & 0.124 & \\
\hline $\begin{array}{l}31 \text { a } 55 \\
\text { años }\end{array}$ & 0.9 & 0.029 & 0.41 & 19 a 30 años & $\begin{array}{c}- \\
1.19\end{array}$ & 0.021 & 3.3 & $\begin{array}{c}\text { Con hijos a los } \\
\text { que lleve al } \\
\text { parque }\end{array}$ & 0.88 & 0.004 & 0.41 & Sexo & -0.58 & 0.052 & 0.56 \\
\hline \multirow[t]{4}{*}{$\begin{array}{l}\text { Reside en } \\
\text { Metepec } \\
\end{array}$} & 0.7 & 0.087 & 0.49 & 31 a 55 años & $\begin{array}{c}- \\
1.38\end{array}$ & 0.004 & 3.98 & & & & & $\begin{array}{l}31-55 \\
\text { años }\end{array}$ & -0.75 & 0.126 & 0.47 \\
\hline & & & & $\begin{array}{l}\text { Educación } \\
\text { Superior }\end{array}$ & 0.65 & 0.06 & 1.92 & & & & & $\begin{array}{l}\text { Más de } \\
55 \text { años }\end{array}$ & -1.64 & 0.166 & 0.19 \\
\hline & & & & $\begin{array}{l}\text { Con hijos a } \\
\text { los que lleve } \\
\text { al parque }\end{array}$ & 0.66 & 0.07 & 1.92 & & & & & & & & \\
\hline & & & & Ingreso C+ & 0.7 & 0.058 & 0.5 & & & & & & & & \\
\hline
\end{tabular}

Tabla 7. Resultados de los modelos de gustos recreativos. Fuente: Elaboración propia con información obtenida en campo. 


\begin{tabular}{|c|c|c|c|c|c|c|c|c|c|c|c|}
\hline \multicolumn{4}{|c|}{$\begin{array}{l}\text { Modelo de días (base: } \sin \\
\text { preferencia) }\end{array}$} & \multicolumn{4}{|c|}{$\begin{array}{l}\text { Modelo de Horario (base: sin } \\
\text { preferencia) }\end{array}$} & \multicolumn{4}{|c|}{$\begin{array}{c}\text { Modelo de Frecuencia ( } \text { no acostumbro } \\
\text { venir) }\end{array}$} \\
\hline Variable & $\beta$ & $\begin{array}{l}\text { Signifi- } \\
\text { cancia }\end{array}$ & $\begin{array}{l}\text { Odds } \\
\text { ratio }\end{array}$ & Variable & $\beta$ & $\begin{array}{l}\text { Signifi- } \\
\text { cancia }\end{array}$ & $\begin{array}{l}\text { Odds } \\
\text { ratio }\end{array}$ & Variable & $\beta$ & $\begin{array}{l}\text { Signifi- } \\
\text { cancia }\end{array}$ & $\begin{array}{l}\text { Odds } \\
\text { ratio }\end{array}$ \\
\hline $\begin{array}{l}\text { Intercepto } \\
\text { (entre } \\
\text { semana) }\end{array}$ & -3 & 0.0068 & & $\begin{array}{l}\text { Intercepto } \\
\text { (mañana) }\end{array}$ & -1 & 0.336 & & $\begin{array}{l}\text { Intercepto } \\
\text { (> de } 5 \text { veces } \\
\text { por mes) }\end{array}$ & 0.08 & 0.8753 & \\
\hline 19-30 años & 2.7 & 0.03 & 15 & $\begin{array}{l}19-30 \\
\text { Años }\end{array}$ & 1.6 & 0.03 & 4.74 & $\begin{array}{l}\text { Intercepto } \\
\text { (1-5 veces por } \\
\text { mes) }\end{array}$ & -2 & 0.0002 & \\
\hline 31-55 años & 3.3 & 0.006 & 26.6 & Ingreso D & 1.5 & 0.099 & 4.28 & 19-30 años & 1.05 & 0.06 & 2.86 \\
\hline$>55$ años & 2.8 & 0.05 & 15.9 & Ingreso D+ & 2 & 0.028 & 7.51 & 31-55años & 1.06 & 0.04 & 2.88 \\
\hline >=Superior & -1 & 0.07 & 0.36 & Ingreso C & 2 & 0.025 & 7.26 & $>55$ años & 2.96 & 0.0002 & 19.3 \\
\hline Ingreso C & 1.4 & 0.02 & 3.86 & Ingreso C+ & 2.9 & 0.031 & 18.3 & En Metepec & 0.66 & 0.02 & 1.94 \\
\hline Ingreso C+ & 2.1 & 0.09 & 8.5 & $\begin{array}{l}\text { Intercepto } \\
\text { (tarde) }\end{array}$ & -1 & 0.25 & & & & & \\
\hline $\begin{array}{l}\text { Con hijos } \\
\text { que lleve } \\
\end{array}$ & -1 & 0.24 & 0.56 & $\begin{array}{l}\text { 19-30 } \\
\text { Años }\end{array}$ & 1.8 & 0.01 & 6.1 & & & & \\
\hline $\begin{array}{l}\text { Intercepto } \\
\text { (fin de } \\
\text { semana) }\end{array}$ & -1 & 0.03 & & Ingreso D & 0.9 & 0.34 & 2.4 & & & & \\
\hline 19-30 años & 1.6 & 0.06 & 4.8 & Ingreso D+ & 2 & 0.03 & 7.44 & & & & \\
\hline 31-55 años & 1.4 & 0.09 & 3.93 & Ingreso C & 1.7 & 0.065 & 5.38 & & & & \\
\hline > 55 años & 0.9 & 0.38 & 2.43 & Ingreso C+ & 0.9 & 0.6 & 2.37 & & & & \\
\hline >=Superior & 0.1 & 0.75 & 1.15 & & & & & & & & \\
\hline Ingreso C & 0.5 & 0.22 & 1.69 & & & & & & & & \\
\hline Ingreso C+ & 1.7 & 0.13 & 5.69 & & & & & & & & \\
\hline $\begin{array}{l}\text { Con hijos } \\
\text { que lleve }\end{array}$ & 0.7 & 0.08 & 2.03 & & & & & & & & \\
\hline
\end{tabular}

Tabla 8. Resultados de los modelos que describen el tipo de visita. Fuente: elaboración propia con datos obtenidos en campo.

disponibles.

- La probabilidad de realizar actividades de relajación disminuye si el visitante tiene hijos a los que lleve al parque y si está en las categorías de edad de 19 a 55 años con respecto a los que tiene 15 a 18 años y es afectada positivamente por la educación superior e ingreso familiar de $\$ 6,800$ a $\$ 11,599$ respectivamente con sus categorías base (educación básica y el nivel de ingreso de $\$ 0$ a $\$ 2,699$ ).

- La probabilidad de participar en actividades de educación ambiental dirigidas a infantes (acompañamiento de niños), disminuye si el visitante es del sexo masculino.

- En cuanto a frecuencia de uso se observa que la probabilidad de visitas más frecuentes se incrementa significativamente a medida que se incrementa la edad y si el visitante procede de Metepec. La relación de edad y frecuencia de visitas es semejante a la encontrada por Kemperman y Timmermans (2006) quienes en un modelo logístico multinomial encontraron que la probabilidad de frecuentar parques se incrementa en categorías de mayor edad. De hecho, ambos autores a $\$ 34,999$.

- Días preferidos. Se encontró un efecto positivo significativo sobre la probabilidad de acudir entre semana, considerando las categorías de edad de 19 a más de 55 años con un efecto mayor en la categoría de 31 a 51 años. La misma relación se observa en las categorías de ingreso que van de $\$ 11,600$ a $\$ 84,999$. Un efecto negativo en la probabilidad se observa si el visitante tiene educación superior. En cuanto a la probabilidad de acudir en fines de semana se observa un efecto positivo en las categorías de edad que van de 19 a 55 años (aunque el efecto es menor que en la ecuación "entre semana"). Igualmente la probabilidad se incrementa si el visitante tiene hijos a los que lleve al parque.

Con estos resultados se puede establecer que el Parque es un espacio público abierto, en donde las actividades recreativas principales son relajación, deporte y particularmente actividades recreativas familiares. Las actividades recreativas son determinadas si los visitantes tienen hijos que llevar al parque (para el caso de actividades familiares), lugar de residencia y edad. Al respecto de esta, se observa que mientras que la probabilidad de hacer depor- 
te se incrementa en el rango de 30 a 55 años, en el mismo rango de edad la probabilidad de realizar relajación y actividades de acompañamiento de educación ambiental disminuye. Igualmente, la probabilidad de frecuentar el parque se incrementa a medida que aumenta la edad. En cuanto al acompañamiento en actividades de educación infantil, es una actividad recreativa que puede estar siendo subutilizada en el parque. Las familias en general no consideran a la educación ambiental como parte de las actividades recreativas favoritas ni como parte principal de sus actividades familiares en el parque. Esto pudiera deberse a que: a) la gente no concibe a las actividades de educación ambiental como una actividad recreativa como lo es llevar a los niños a los juegos o pasear con la familia en las áreas verdes sino más bien como una actividad solamente educativa; b) es una actividad que dentro del parque se promueve y dirige principalmente a niños y niñas y no a toda la familia. De hecho se preguntó a los encuestados ¿A quién considera que se deben dirigir las actividades de educación ambiental que se realizan en el parque? Obteniéndose, que el $41 \%$ de los visitantes mencionaron que dichas actividades deben dirigirse a todas las personas por igual, sin importar edad; frente a un $36 \%$ que menciono que principalmente a niños y el resto a adolescentes (7.6\%); padres de familia (8.7\%) y el resto se distribuyó en adultos y adultos mayores. Al respecto Rico (2005), señala que para que la recreación pueda dinamizar procesos de educación ambiental es necesario que la recreación con objetivos ambientales se persiga a lo largo de toda la vida, igualmente establece que la experiencia estadounidense ha cubierto programas dirigidos a personas en edad escolar, pero también programas educacionales ambientales para adultos. Consecuentemente, se recomienda que los administradores del parque consideren desarrollar programas de educación ambiental dirigidas a personas de diferentes edades y actividades lúdicas ambientales que incluyan a todos los integrantes de la familia bajo un concepto de equidad e inclusión social para comprender los diversos tipos de familia: mamás solteras, papás solteros, familias nucleares, familias extendidas, familias reconstituidas, familias homoparentales, otras. (Flores-Xolocotzi y González Guillén, 2007). Esta equidad e inclusión se sugiere se extienda al resto de actividades recreativas que se organicen dentro del parque como actividades deportivas y generar programas recreativos incluyentes que comprendan una combinación de actividades deportivas, actividades familiares y educación ambiental.

\section{Calidad del parque}

Sobre este aspecto y considerando los servicios recreativos que ofrece el parque se tuvo que: $45.7 \%$ de los visitantes consideran que el parque tiene una calidad excelente; mientras que el $51 \%$ y $13.2 \%$ lo consideran bueno y regular respectivamente. No obstante, los visitantes perciben una serie de problemas y necesidades no cubiertas dentro del espacio que deberán ser considerados por los administradores del parque, particularmente el problema de la basura fuera de los botes, falta de botes de basura y falta de bancas. (Tabla 9).

\begin{tabular}{|l|c|}
\hline Problema observado & $\%$ \\
\hline Basura fuera de los botes & 12.5 \\
\hline Falta de bancas & 39 \\
\hline Falta de botes de basura & 25 \\
\hline Personas que tiran basura fuera de los botes & 20 \\
\hline Agresiones entre visitantes & 4.3 \\
\hline
\end{tabular}

Tabla 9. Problemas observados por los visitantes. Fuente: elaboración propia a partir de trabajo de campo.

Otro aspecto, que deberá ser considerado por los administradores del espacio y que amerita futuras investigaciones es, la interacción entre visitantes cuyos gustos recreativos pueden contraponerse, además de la relación entre actividades deportivas, diseño del parque y reglas de uso del equipamiento deportivo. Es el caso del uso de la de la bicipista, trotapista y equipamiento deportivo para adultos. Se encontró que $6 \%$ de los usuarios reportan problemas de congestión y de conflicto con usuarios que van en bicicleta en ambos sentidos y a velocidades que ponen en riesgo a niños que van en triciclos y bicicletas. La falta de claridad y/o desconocimiento en las reglas de uso, incide también con el uso de equipamiento deportivo dirigido exclusivamente a adultos; ya que $3.3 \%$ de los visitantes expresaron molestias hacia niños que hacen uso de aparatos de gimnasio con el consentimiento de los padres (en algunos casos se reportó reclamos verbales entre usuarios y padres de los infantes). En el caso de los andadores, que al mismo tiempo son empleados como trotapista, $2.7 \%$ de visitantes expresaron molestias al compartir los mismos andadores (acondicionados con arcilla para trote) con corredores, debido a que estos escupen sobre la pista y van a velocidades que interfieren con el caminar de las familias. Igualmente, hay que considerar que los andadores son de arcilla y en algunos casos de grava, lo cual dificulta el acceso de personas con capacidades diferentes (en silla de ruedas, muletas, bastón) o que lleven carreolas con bebés. Relacionado con reglas de uso $3.8 \%$ de visitantes reportaron la presencia de visitantes que metían perros al parque, pese a los señalamientos de prohibición en las entradas del parque. Hay que acotar que el diseño del parque no consideró andadores para circulación exclusiva de peatones, sino que los andadores a lo largo del parque tienen que compartirse con personas que se ejercitan en trote y carrera. No así con ciclistas, que por reglas del parque sólo deben pedalear en la bicipista. Considerando que el parque se inauguró apenas en 2009, el número y densidad de visitantes puede incrementarse con el tiempo (no existen estadísticas de visitantes sistematizadas), por lo tanto existe un riesgo de conflicto entre usuarios con diferentes necesidades y gustos. Por último, hay que mencionar, que aunque no existen estadísticas nacionales mexicanas sobre actividades recreativas en parques urbanos, el Instituto de Mercadotecnia y Opinión (IMO, 
2009) ha realizado un estudio nacional sobre tiempo libre, recreación y deporte, en este estudio se menciona que para los mexicanos los principales factores que esgrimen los mexicanos para realizar actividades recreativas en su tiempo libre son en orden de descendente de importancia: falta de instalaciones cercanas, falta de tiempo, necesidad de cuidar a alguien (adultos mayores, niños, otros), falta de dinero, salud de la persona, edad o discapacidad como obstáculo. Consecuentemente, es necesario que los administradores del espacio consideren: a) consensuar y socializar las reglas de uso de equipamiento y servicios que ofrece el parque, a través de talleres participativos, reuniones o pláticas; b) adecuar las instalaciones del parque para evitar conflictos entre los diferentes tipos de usuario, como por ejemplo, elaborar andadores de uso exclusivo para peatones con las adecuaciones necesarias para que accedan personas con capacidades diferentes, adultos mayores, personas que llevan niños en carreolas; y c) desarrollar/promover programas recreativos incluyentes para todo tipo de personas y/o familias. Finalmente en futuras investigaciones será necesario considerar la opinión de aquellas personas que visitan por primera vez el parque (no considerada en esta investigación), ya que son un segmento de visitantes potenciales del parque, cuyas expectativas de gustos y preferencias recreativas tendrían que ser consideradas, para atraer a un segmentos de la población que pudiera no estar aprovechando el potencial recreativo del parque.

\section{Conclusiones y recomendaciones}

1. Los resultados permiten concluir que el parque es visitado principalmente por gente de Metepec (46.9\%) y las actividades recreativas preponderantes son tres: deporte, recreación familiar (llevar a los niños a los juegos, convivir y pasear con la familia), relajación y en menor proporción actividades de educación ambiental, en esta última la gente acompaña a los niños en actividades educativas promovidas y dirigidas particularmente a infantes.

2. Con relación al análisis de los gustos recreativos, éstos se encuentran correlacionados particularmente con la edad y si el visitante tiene hijos a los que lleve al parque. Del conjunto de gustos recreativos, las actividades recreativas principales son: relajación, deporte y particularmente actividades recreativas familiares. Sin embargo existe un grupo socioeconómico con ingreso de \$ 0-\$2,699 que no realizan actividades de relajación, no consumen alimentos, tampoco educación ambiental, ver el paisaje, ni realizan otras actividades (leer, platicar o jugar), pero que sin embargo no se observa una correlación o preferencia de peso por las actividades restantes: deporte y recreación familiar. Por lo tanto, futuras investigaciones deberán profundizar en los gustos recreativos de este grupo social que socioeconómicamente es vulnerable.

3. Sobre preferencias de visita (días, horarios y frecuencia de visita), se concluye particularmente que la edad es determinante, particularmente en el caso de frecuencia de visita en donde se observa una relación positiva entre ambas variables.

4. Las actividades recreativas a destacar por ser estadísticamente significativas son: para el caso de recreación familiar, si los visitantes tienen hijos que llevar al parque. Para actividades deportivas por lugar de residencia en Metepec y edad de 31 a 55 años. Para actividades de relajación el nivel de ingreso $\mathrm{C}+(\$ 35,000$ a $\$ 84,999)$ y negativamente por los rangos de edad de entre 19 a 30 y 31 a 55 años, por tener hijos que llevar al parque y si la persona tiene niveles de educación superior.

5. En cuanto a las actividades de educación ambiental infantil, se concluye que es una actividad que está siendo subutilizada en el parque, las familias en general no consideran a la educación ambiental como parte fundamental de las actividades recreativas familiares en el parque. Esto pudiera deberse a que la educación ambiental no se concibe como actividad recreativa o bien a que es una actividad que principalmente se promueve a niños y no a toda la familia. No obstante, se tiene que considerar que el $41 \%$ de los visitantes menciona que dichas actividades deben dirigirse principalmente a todas las personas por igual, sin importar edad; frente a un $36 \%$ que menciono que principalmente a niños

6. Aunque que $45.7 \%$ y $51 \%$ de los visitantes consideran que el parque tiene una calidad excelente y buena respectivamente, se perciben molestias entre usuarios que hacen uso de la bicipista, trotapista y equipamiento deportivo hacia personas que hacen uso indebido de ello (niños que hacen uso de equipo deportivo de adultos) o que afectan las actividades recreativas de otros, por ejemplo: ciclistas que van a altas velocidades en una pista que es usada por niños (lo cual se agudiza debido a problemas de congestión) o el caso de la trotapista que tiene que ser compartida por corredores y gente (familias) que caminan tranquilamente para dirigirse a otros sitios del parque .

Considerando lo anterior se recomiendan las siguientes acciones:

1. Se sugiere que los administradores del parque consideren desarrollar y organizar actividades recreativas (deporte, recreación familiar, actividades de educación ambiental, otras) bajo un concepto de equidad e inclusión social para comprender a todos los grupos sociales que acuden al parque e igual programar actividades recreativas desde una perspectiva integral deportiva, familiar y de educación ambiental.

2. Se sugiere que los administradores consensuen, socialicen y promuevan las reglas de uso de equipamiento y servicios que se ofrecen, particularmente de las pistas para ciclismo y trote. Una forma de socializar las reglas de uso serían a través de talleres o bien a través de los mismos eventos recreativos que se organicen dentro del parque.

3. Por último se considera necesario adecuar las insta- 
laciones del parque para evitar conflictos entre los diferentes tipos de usuario, particularmente considerar el desarrollo de andadores exclusivos para peatones y con facilidades de acceso para personas con capacidades diferentes.

\section{Agradecimientos}

La fase de campo de esta investigación se realizó como parte de una estancia posdoctoral en el Programa de Estudios Urbanos y Ambientales del Colegio Mexiquense A.C., contando con el apoyo monetario del Consejo Nacional de Ciencia y Tecnología de México, además del apoyo técnico del Colegio Mexiquense y del Dr. Alfonso X. Iracheta Cenecorta.

\section{Bibliografía}

Abercrombie L., J. Sallis, T. Conway, L. Frank, B. Saelens, J. Chapman

2008 "Income and racial disparities in acces to public parks and private recreation facilities", American Journal of Preventive Medicine, 34(1): 9-15.

Agresti, A.

2007 An introduction to categorical data analysis, John Wiley \& Sons, Inc., New Jersey, United States of America.

Arcarons J. y S. Calonge

2008 "Microeconometría. Introducción y aplicaciones con software econométrico para Excel”, Delta Publicaciones, Madrid, España.

Asociación Mexicana de Agencias de Investigación de Mercado y Opinión Pública A.C. (AMAI)

2006 "Avances AMAI: Distribución de niveles socioeconómicos en el México urbano", Revista AMAI segunda época, 1(6): 1-7.

Bengochea A., M. Fuentes y S. Del Saz

2007 "Análisis conjunto y espacios naturales: una aplicación al Paraje Natural del Desert de les Palmes", Investigación agraría: sistemas y recursos forestales, 16(2):158-168.

Casals, N. y G. Olivares,

1999 "Percepción y selección del espacio recreativo", Gestión Turística, 1(4): 51-57.

Chiesura, A.

2004 "The role of urban parks for the sustainable city", Landscape and Urban Planning, 68(1):129-138.

Cho, C.J.

1993, "The measure of locational efficiency of urban parks: the case of Chonju", Urban Studies, 30(8): 1399-1407.

De Frutos, P.

2004, "Determinantes de las visitas a los parques y jardines urbanos: aplicación de un modelo gravitatorio", Estudios de economía aplicada, 22(2):349-363.

Dumitras, D. y S. Dragoi

2007. "Analysis of tourist's preferences for public recreation areas", Bulletin of University of Agricultural Sciences and Veterinary Medicine Cluj-Napoca. Hor- ticulture, 64(1-2):333-338.

Falcón, A.

2007 Espacios verdes para una ciudad sostenible, Editorial Gustavo Gilli, Barcelona, España.

Garrido, A. y Y. Polo

Flores-Xolocotzi, R. y M. González-Guillén

2007, Consideraciones sociales en el "Consideraciones sociales en el diseño y planificación de parques urbanos", Economía, Sociedad y Territorio 6(24): 913-951.

Flores-Xolocotzi, R.

2011, "Actividades recreativas en el Parque Hundido del Distrito Federal (México)", Estudios y perspectivas en turismo, 20 (4): 797-823.

Garrido A. y Y. Polo

2002 "Tipología de comportamiento en el lanzamiento de nuevos productos: relaciones entre decisiones estratégicas y tácticas de influencia en el resultado", XIV Encuentro de Profesores Universitarios de Marketing, Granada, España.

Golob, T. y A. Regan

2002 "The perceived usefulness of different sources of traffic information to trucking operations", Transportation Research Part E, 38(1): 97-116.

Gobierno Municipal de Metepec

2008 Plan municipal de desarrollo urbano de Metepec, Gobierno Municipal de Metepec, Metepec, Estado de México.

Google Inc.

2010 Google Earth, (versión 5.2 para Windows), California, Estados Unidos de Norteamérica.

Guerrero M., A. Santiago y C. Bouza

2009 "El Mercado turístico de Acapulco: estudio de la autorrealización y del autoconcepto", Revista académica de marketing aplicado, 1(1):83-149.

Hammit, W., R. Bixler, y F. Noe

1996 "Going beyond importance performance analysis to analyze the observance-influence of park impacts", Journal of Park and Recreation Administration, 14(1): 45-62.

Iazzetta, E.

2002 "Una metodología de planificación turística y recreacional para parques urbanos en frentes de agua", Cuadernos de Turismo, 1(10): 167-180.

Instituto de Mercadotecnia y Opinión (IMO)

2009 El tiempo libre de los mexicanos en un estudio comparado con otros países, Ciudad de México, México.

Instituto Nacional de Estadística Geografía e Informática (INEGI)

2004 Delimitación de las zonas metropolitanas de México, Instituto Nacional de Estadística Geografía e Informática, Aguascalientes, México.

Instituto Nacional de Estadística Geografía e Informática (INEGI)

2008 II Conteo de población y vivienda 2005. México y sus municipios, Instituto Nacional de Estadística Geografía e Informática, Aguascalientes, México.

Kemperman, A. y P. Timmermans

2006 "Heterogeneity in urban parks use of aging visitors: 
a latent class analysis", Leisure Sciences, 28(1): 57-71. Low, S., D. Taplin y S. Scheld

2005 Rethinking Urban Parks. Public Space and Cultural Diversity, The University of Texas Press, Austin.

López, H.

2009 Nivel socioeconómico AMAI, Comité Niveles Socioeconómicos AMAI, Instituto de Investigaciones Sociales, S.C., disponible en http://www.amai.org/NSE/NivelSocioe conomicoAMAI.pdf [Accesado el 1 de octubre de 2010].

Meulman J. y Heiser W.

2007 SPSS Categories 17, SPSS Inc. Chicago, United States of America.

Oguz, D.

2000 "User surveys of Ankara's urban parks", Landscape and Urban Planning, 52(1): 165-171.

Payne L., Mowen, A., y Orsega-Smith, E.

2002 "An examination of park preferences and behaviors among urban residents: the role of residential location, race and age", Leisure Sciences, 24(1): 181-198.

Rico, C,

2005 "Recreación y educación ambiental", Disponible en http:// www.funlibre.org/documentos/RyEAmbiental. html\#Uso_apropiado_del_documento [Accesado el 1 de agosto de 2011].

Santos, J., Muñoz Á., Martel, P. y Cortiñas, P.

2003 Diseño de encuestas para estudios de mercado: técnicas de muestreo y análisis multivariante, Editorial Areces, Madrid, España.

Sánchez-Gasca, C.

2009 "Esfuerzos públicos para la creación del Parque Ambiental Bicentenario", Congreso Los Caminos de la Sustentabilidad ante el Cambio Climático, Octubre de 2009. Disponible en http://www.salvemossedagro. org/2009/10/presentacion-del-caso-parque-ambiental_13.html [Accesado el 1 de junio de 2010].

Sasidharan, V., F. Willits y G. Godbey

2005 "Cultural differences in urban recreation patterns: an examination of park usage and activity participation across six population subgroups", Managing Leisure, 10(1): 19-38.

Secretaría de Desarrollo Social (SEDESOL)

1999 Sistema normativo de equipamiento urbano, Tomo V Recreación y deporte, Secretaría de Desarrollo Social Distrito Federal, México ${ }^{0} 1$, disponible en http:// www.salvemossedagro.org/2009/10/presentacion-delcaso-parque-ambiental_13.html, [Accesado el 1 de junio de 2010].

Stynes D., D. Spotts y J. Strunk

1985, "Relaxing assumptions of perfect information in park visitation models", Professional Geographer, 37(1): 21-28.

Taylor W., W. Poston, L. Jones y K. Eating

2006 "Environmental justice: obesity, physical activity, and healthy eating", Journal of Physical Activity and Health 3(1):30-54.

Vera, C.

2005 "Recreación y comunidad", Recreación, Cuadernos de Divulgación del Grupo Recreando, disponible en http://www.recreacionnet.com.ar/pages28/articulos3. html, [Accesado el 1 de octubre de 2010].

Yazici A., E. Ögüs, H. Ankarali y F. Gürbüz 2010 "An application of nonlinear canonical correlation analysys on medical data", Turkish Journal Medical Science, 40(1): 1-8.

Yilmaz S., M. Zengin, N. Yildiz

2007, "Determination of user profile at city parks: A sample from Turkey", Building and Environment, 42 (1): 2325-2332.

Recibido:

$08 / 11 / 2010$

Reenviado:

$07 / 09 / 2011$

Aceptado:

$15 / 10 / 2011$

Sometido a evaluación por pares anónimos 